Fourth International Conference on Sustainable Construction Materials and Technologies http://www.claisse.info/Proceedings.htm

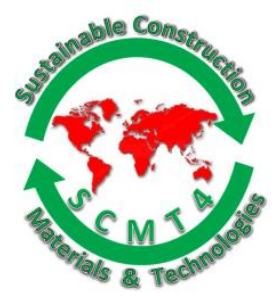

SCMT4

Las Vegas, USA, August 7-11, 2016

\title{
Study on Properties of High Fluidly Concrete with Three Kinds of Powder
}

\author{
Akira Irie $^{1 \mathrm{a}}$, Takasu Koji ${ }^{1 \mathrm{~b}}$, Koyamada Hidehiroo ${ }^{1 \mathrm{c}}$, and Suyama Hiroki ${ }^{1 \mathrm{~d}}$ \\ ${ }^{1}$ The University of Kitakyusyu - 1-1 Hibikino Wakamatsu-ku Kitakyushu, Fukuoka, 808-0135, Japan, \\ ${ }^{1 a}$ Email: <w5mbb003@eng.kitakyu-u.ac.jp >, ${ }^{1 b}$ Email: $<w 5 m b b 003 @ e n g . k i t a k y u-u . a c . j p>$,

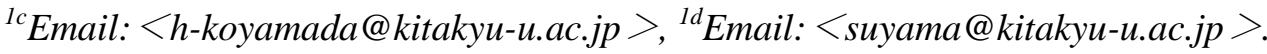

\begin{abstract}
The mixture of concrete with fly ash and limestone powder was exhibited a similar slump flow at almost the same with agent addition rate though interchanged the substitution rate of these powders. In the mixture with large amount of powder, it was thought that the distance between particles in concrete is narrowed very much. In addition it was thought that the amount powder particle increased, a free water content decreased, and concrete fluidly decreased. It is thought to made a reduction in the fluidity of the concrete. An increase in the water content or an increase super plasticizer was thought as a corrective strategy of fluidly.
\end{abstract}

\section{INTRODUCTION}

A variety of by-product powder have been exhausted by the industrial world now. The method of use as the mixture for use in concrete is devised as a method of using there. However the fluidly of concrete that mixed the compound as for the powder was hardly researched. This study focused on properties of high fluidly concrete by using large amount of powder. We researchd change in the slump flow by the influence of the amount of the agent and powders. That used two kind of fine aggregate(Sea sand and Crushed sand) and three kind of powders(Fly ash, Limestone powder and Crushed stone powder).

\section{EXPERIMENTAL PROGRAM}

Table1 shows materials in this experiment. To prepare a normal strength concrete with compressive strength of approximately $f_{\mathrm{c}}=30 \mathrm{~N} / \mathrm{mm}^{2}$ we used $30 \%$ fly ash with cement. We next used limestone powder or crushed stone powder as a fine aggregate substitute at substitution rates of $5 \%, 10 \%$, and $15 \%$. In mixtures with $5 \%$ and $10 \%$ powder, we increased the fly ash content until the substitution rate reached $15 \%$ of the total amount. Table 2 shows mix proportions. The number following each letter is used to designate the substitution rate with respect to the volume of powder introduced as a fine aggregate substitute. The unit quantity of water for all mixtures was $180 \mathrm{~kg} / \mathrm{m}^{3}$. Air-entraining and highrange water-reducing admixture and air content stabilizers were used to reach a target slump flow of $650 \mathrm{~mm}+50-100 \mathrm{~mm}$ and target air content of $4.5 \% \pm 1.0 \%$. Figure 1 shows the picture of V-funnel drop test. Immediately after kneading, a V-funnel drop test was performed in compliance with JSCEF512, "Method for performing high-fluidity concrete drop testing using a funnel." 
Table 1. Materials

\begin{tabular}{|c|c|c|c|}
\hline & Kind & Property & Symbol \\
\hline Cement & $\begin{array}{c}\text { Ordinary portland } \\
\text { cement }\end{array}$ & Density:3.16 $\left[\mathrm{g} / \mathrm{cm}^{3}\right]$ & $\mathrm{C}$ \\
\hline Water & Tap water & - & $\mathrm{W}$ \\
\hline \multirow{7}{*}{ Admixture } & \multirow{3}{*}{ Fly ash } & Density: $2.43\left[\mathrm{~g} / \mathrm{cm}^{3}\right]$ & \multirow{3}{*}{ FA } \\
\hline & & Ignition loss:1.67[\%] & \\
\hline & & Specific surface area: $4270\left[\mathrm{~cm}^{2} / \mathrm{g}\right]$ & \\
\hline & \multirow{2}{*}{ Limestone powder } & Density: $2.74\left[\mathrm{~g} / \mathrm{cm}^{3}\right]$ & \multirow{2}{*}{ LP } \\
\hline & & 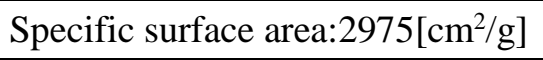 & \\
\hline & \multirow{2}{*}{$\begin{array}{l}\text { Crushed stone } \\
\text { powder }\end{array}$} & Density $2.70\left[\mathrm{~g} / \mathrm{cm}^{3}\right]$ & \multirow{2}{*}{ CSP } \\
\hline & & Specific surface area: $4624\left[\mathrm{~cm}^{2} / \mathrm{g}\right]$ & \\
\hline \multirow{4}{*}{$\begin{array}{c}\text { Coarse } \\
\text { Aggregate }\end{array}$} & \multirow{4}{*}{ Crushed stone } & $\begin{array}{c}\text { Density in saturated } \\
\text { surface-dry: } 2.70\left[\mathrm{~g} / \mathrm{cm}^{3}\right]\end{array}$ & \multirow{4}{*}{ G } \\
\hline & & $\begin{array}{c}\text { Coefficient of } \\
\text { water absorption: } 1.41[\%]\end{array}$ & \\
\hline & & Fineness modulus: 6.9 & \\
\hline & & Solid content: $63 \%$ & \\
\hline \multirow{8}{*}{$\begin{array}{c}\text { Fine } \\
\text { Aggregate }\end{array}$} & \multirow{4}{*}{ Sea sand } & $\begin{array}{c}\text { Density in saturated } \\
\left.\text { surface-dry:2.59[g/ } / \mathrm{cm}^{3}\right]\end{array}$ & \multirow{4}{*}{$\mathrm{S}$} \\
\hline & & $\begin{array}{c}\text { Coefficient of } \\
\text { water absorption:0.76[\%] }\end{array}$ & \\
\hline & & Fineness modulus: 2.4 & \\
\hline & & Solid content:61.5[\%] & \\
\hline & \multirow{4}{*}{ Crushed stone sand } & $\begin{array}{c}\text { Density in saturated } \\
\left.\text { surface-dry:2.66[g/cm }{ }^{3}\right]\end{array}$ & \multirow{4}{*}{ CS } \\
\hline & & $\begin{array}{c}\text { Coefficient of } \\
\text { water absorption:1.96[\%] }\end{array}$ & \\
\hline & & Fineness modulus:3.1 & \\
\hline & & Solid content:57.1[\%] & \\
\hline Agent & Super plasticizer & Polycarboxylic Acid-base & SP \\
\hline
\end{tabular}

Table 2. Preparations

\begin{tabular}{|c|c|c|c|c|c|c|c|c|c|}
\hline \multirow{2}{*}{ Preparation Sign } & \multirow{2}{*}{$\begin{array}{c}\text { W/P } \\
{[\%]}\end{array}$} & \multicolumn{8}{|c|}{ Unit Content $\left[\mathrm{kg} / \mathrm{m}^{3}\right]$} \\
\cline { 3 - 10 } & 50 & 180 & 360 & 0 & 0 & 0 & 786 & 0 & 966 \\
\hline N50S & 50 & 180 & 360 & 0 & 0 & 0 & 0 & 807 & 966 \\
\hline N50CS & 23 & 180 & 252 & $\begin{array}{c}108 \sim \\
344\end{array}$ & $\begin{array}{c}139 \sim \\
416\end{array}$ & 0 & 367 & 0 & 966 \\
\hline LP5 $15 S$ & 23 & 180 & 252 & $\begin{array}{c}108 \sim \\
344\end{array}$ & $\begin{array}{c}139 \sim \\
416\end{array}$ & 0 & 0 & 377 & 966 \\
\hline LP5 $15 \mathrm{CS}$ & 23 & 180 & 252 & $\begin{array}{c}108 \sim \\
344\end{array}$ & 0 & $\begin{array}{c}138 \sim \\
413\end{array}$ & 367 & 0 & 966 \\
\hline CSP5 15S & & & & & & & & \\
\hline
\end{tabular}




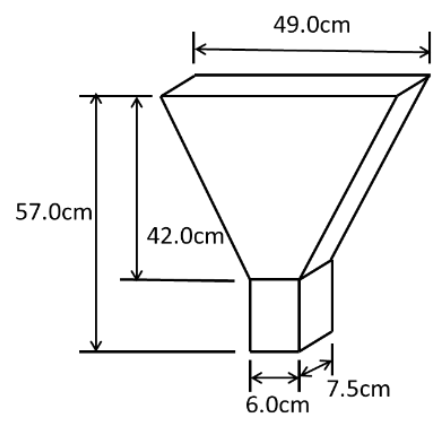

Figure 1. V-funnnel DropTest

\section{RESULTS AND DISCUSSIONS}

Agent addition rate and Admixture substitution rate. Figure 2 shows the relation between the agent addition rate needed to maintain the prescribed slump flow value and the substitution rate of limestone powder or crushed stone powder as a fine aggregate substitute. As shown in the figure, the agent addition rates were higher in concrete containing crushed stone power than in concrete containing limestone powder. Furthermore, for concrete using limestone powder, no significant change in the agent addition rate was found when producing concrete with a given slump flow value while varying the fine aggregate substitution rate. However, for concrete using crushed stone powder, the agent addition rate became very large as the fine aggregate substitution rate was increased. Previous studies have reported that limestone powder and fly ash have similar BET surface areas, while that of crushed stone powder is larger. Therefore, crushed stone powder absorbs more admixture during kneading and thus requires a higher admixture amount. Consequently, in cases where fly ash and limestone powder are used in combination, even in the same usage amounts and even when the substitution ratios of fly ash and limestone powder as aggregates are different, it is possible that no large variation in the admixture addition amount will be seen. One can presume that a significant increase in the amount of admixture used in high-flow concrete with crushed stone powder will increase costs and make workability more difficult to manage. Focusing on differences between the fine aggregates, concretes using limestone powder did not show a large difference in the agent addition rate, but concretes using crushed stone powder had a larger value. Previous studies have found that when the solid content rate of fine aggregates is low or the quantity of material finer than a $75-\mu \mathrm{m}$ is high, changing the slump by $1 \mathrm{~cm}$, whether increasing or decreasing, requires more water. The crushed sand used in this study had a smaller solid content rate than sea sand, so differences in the fine aggregate may have resulted in the different agent addition rate.

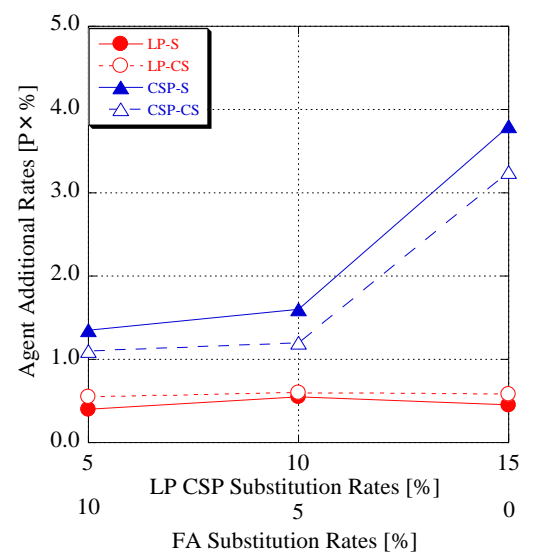

Figure 2. The Relation Between Agent Addition Rate and the Substitution Rates for Each Powders 
Fluidity and Viscosity. Figure 3 shows the changes of fresh properties resulting from variations in the type of powder, substitution rate, and fine aggregate type as obtained from a slump flow test. Focusing on concrete containing limestone powder, we found that the unit quantity of water, the fine aggregate substitution rate, or type of fine aggregate did not result in significant changes in the time required for a 500-mm slump flow test. This suggests that when mixing fly ash and limestone powder, it is not necessary to calculate the effects of admixtures for each powder; the powder can be treated as a single entity. As for concrete using crushed stone powder, the prescribed slump flow values stayed within $650 \mathrm{~mm}+50-100 \mathrm{~mm}$, whereas the time required to complete a 500-mm slump flow varied greatly. This is likely because fly ash has a nearly spherical shape with little roughness but the surface of crushed stone powder has extensive fine roughness, meaning that as the substitution rate of crushed stone power is increased, the amount of water adhering to it is greater than that adhering to the same volume of fly ash.
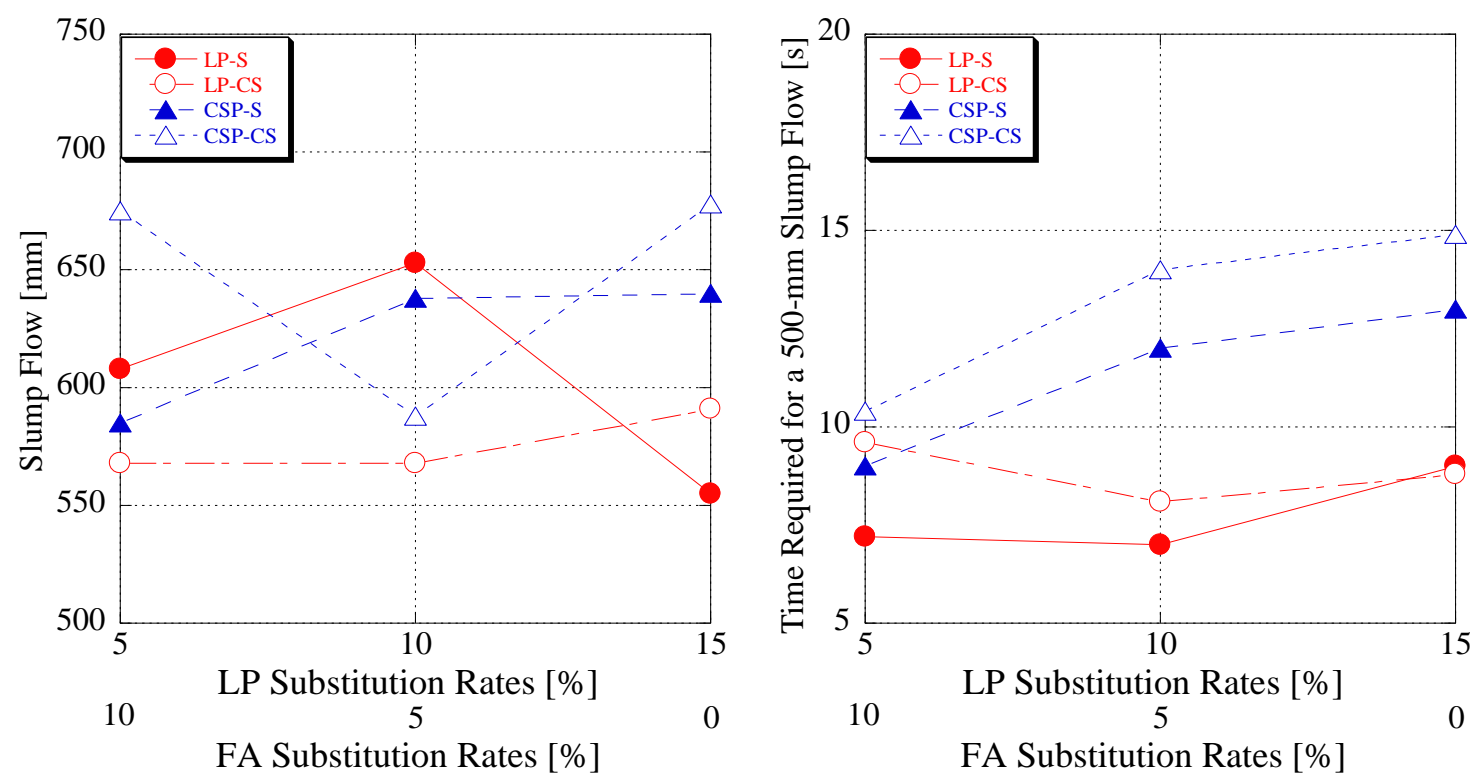

Figure 3. Changes of Fresh Properties resulting from variations in the type of powder

Figure 4 shows the relations between $\mathrm{R}_{\mathrm{c}}$, which is the relative V-funnel drop test rate used as a method for evaluating the viscosity of high-flow concrete, and $\Gamma_{\mathrm{c}}$, which is the relative flow area ratio used to evaluate concrete deformation. While there is some variation between $R_{c}$ and $\Gamma_{c}$ for concrete using limestone powder, a positive correlation is seen. As $R_{c}$ increases, phenomena such as material separation even within slump flow management values can be seen, likely indicating an increase in $\Gamma_{\mathrm{c}}$. Although variations in the slump flow value are seen for concrete using crushed stone powder, no significant change in $\Gamma_{\mathrm{c}}$ is evident. In other words, the viscosity of the concrete was not largely affected. In Eq. (1), values of 4-20 s $\left(R_{c}=0.5-2.5\right)$ are generally recommended for the $V$-funnel drop time. None of the drop times reached the recommended values for any type of concrete, but within the ranges of this study, further increasing the unit quantity of water or adding a water-reducing agent introduces the danger of material separation. Future studies should address how to mix concretes with the proper viscosity.

$\mathrm{R}_{\mathrm{c}}=10 / \mathrm{t} \quad \ldots(1) \quad \Gamma_{\mathrm{c}}=(\mathrm{fa} / 20)^{2}-1 \ldots(2)$

$\mathrm{t}$ : Relative V-funnel Drop Test Rate [s] fa : Slunp Flow [cm] 


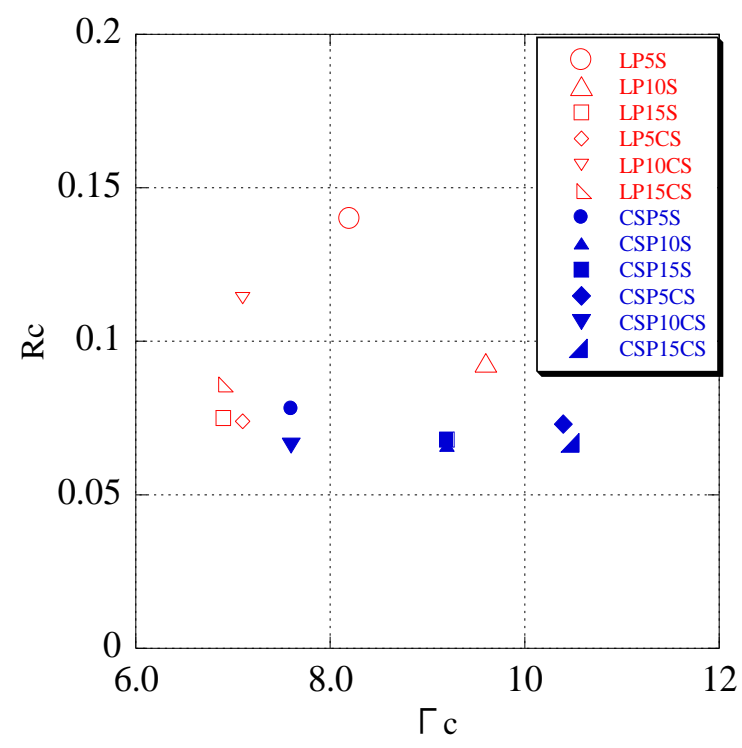

Figure 4. Relations between $R_{c}$ and $\Gamma_{c}$

Compressive strength. Figure 5 shows compressive strength of concretes. Compressive strength of approximately $f_{\mathrm{c}}=24 \mathrm{~N} / \mathrm{mm}^{2}$ at a material age of 28 days and $f \mathrm{c}=30 \mathrm{MPa}$ at a material age of 56 days was demonstrated. Concretes containing sea sand and crushed sand mixtures were prepared, and in almost all cases, crushed sand showed better results for promoting compressive strength. Previous studies have found that compared with the use of sea sand, the use of crushed sand results in increased concrete density, and the use of large amounts of admixture as in the case here resulted in a similar phenomenon. Comparing concretes with and without admixture, almost all the concretes with admixture showed higher strength development. This is likely because substituting a large amount of powder for fine aggregate results in better filling of aggregate voids within the concrete by small powder particles, thus increasing density.

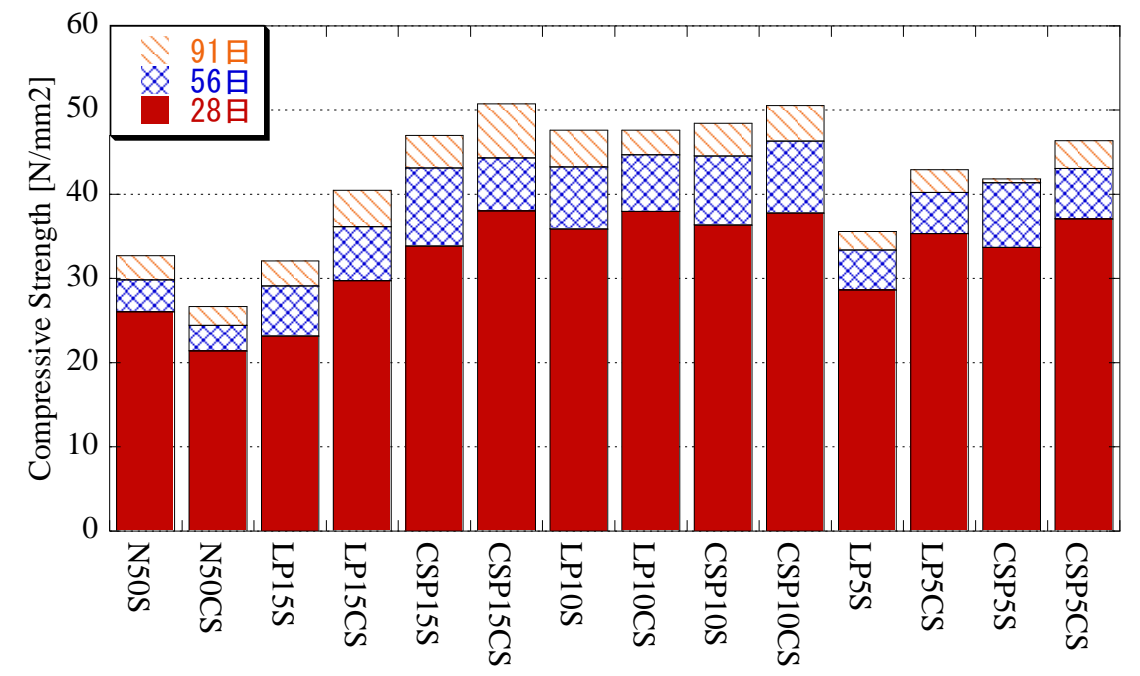

Figure 5. Compressive Strength

Static modulus of elasticity. Figure 6 shows the relations between static modulus of elasticity and compressive strength. The graph shows the results of analysis when coefficients $k_{1}$ and $k_{2}$ in the New $\mathrm{RC}$ equation are set to 1.0 and the mass per unit volume is set to 2.32 . Generally speaking, increasing the mass per unit volume also increases the static modulus of elasticity. The concrete used in this experiment was prepared with cement containing $20 \%$ of fly ash, and furthermore fly ash replaced 0 
$10 \%$ of the fine aggregate. Because cement and fine aggregate are replaced by fly ash - the material with the lowest density used in this experiment - the unit bulk density is lowered in comparison with concrete not including an admixture. This is likely why concrete with a fly ash admixture exhibited a trend for lower elasticity. However, the concrete prepared with admixture in this experiment used large amounts of limestone powder or crushed stone powder in an outer percentage range of $5-15 \%$ as a substitute for fine aggregate, and these powders have a higher density than that of fine aggregate. This increases the unit bulk density of the concrete, leading to an static modulus of elasticity equal to or exceeding that of concrete with admixture.

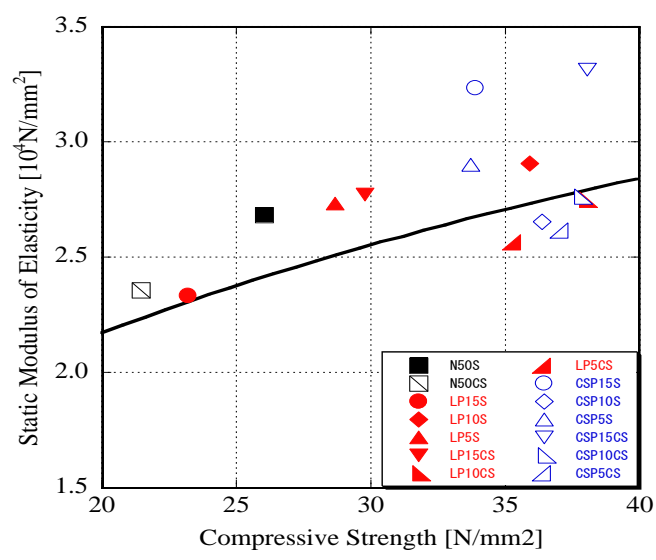

\section{Figure 6. Relations between static modulus of elasticity and compressive strength}

\section{CONCLUSION}

The following general conclusions can be drawn from the study provided in the paper:

- For concrete using limestone powder, no significant change in the agent addition rate was found when producing concrete with a given slump flow value while varying the fine aggregate substitution rate. However, for concrete using crushed stone powder, the agent addition rate became very large as the fine aggregate substitution rate was increased.

- When mixing fly ash and limestone powder, it is not necessary to calculate the effects of admixtures for each powder; the powder can be treated as a single entity. As for concrete using crushed stone powder, the prescribed slump flow values stayed within $650 \mathrm{~mm}+50-100 \mathrm{~mm}$, whereas the time required to complete a $500-\mathrm{mm}$ slump flow varied greatly.

- Although variations in the slump flow value are seen for concrete using crushed stone powder, no significant change in $\Gamma_{\mathrm{c}}$ is evident. In other words, the viscosity of the concrete was not largely affected.

- Compressive strength of approximately $f_{\mathrm{c}}=24 \mathrm{~N} / \mathrm{mm}^{2}$ at a material age of 28 days and $f \mathrm{c}=30 \mathrm{MPa}$ at a material age of 56 days was demonstrated. Concretes containing sea sand and crushed sand mixtures were prepared, and in almost all cases, crushed sand showed better results for promoting compressive strength.

- Limestone powder and crushed stone powder have a higher density than that of fine aggregate. This increases the unit bulk density of the concrete, leading to an static modulus of elasticity equal to or exceeding that of concrete with admixture.

\section{ACKNOWLEDGEMENT}

This work was supported by JSPS KAKENHI Grant Number 22760424. The experiment was supported by Eiji Mikura, Kazuyuki Miura, and Youichi Nagata. We show gratitude to them. 


\section{REFERENCES}

Akira Irie, Koji Takasu, Study on properties of high fluidly concrete with three kind of powder, Architectual Institute of japan, pp265-266, Japan(2015)

Japan Standards Association:JIS HB Ready mixed Concrete-2014 